\title{
Farming system design to feed the changing world. A review
}

\author{
Guillaume Martin • Roger Martin-Clouaire • \\ Michel Duru
}

Accepted: 13 December 2011 / Published online: 27 January 2012

(C) The Author(s) 2012. This article is published with open access at Springerlink.com

\begin{abstract}
Agricultural production is unstable as a result of complex, dynamic and interrelated factors such as climate, markets and public policy that are beyond farmers' control. Farmers must therefore develop new farming systems incorporating innovations in objectives, organization and practices adapted to changing production contexts. As a consequence, agronomists have expanded the "farming system design" field of research. A variety of quantitative and qualitative design approaches have been developed to support the analysis of current farming systems and the design and evaluation of alternatives. A comprehensive literature assessment is lacking for this emerging field of agricultural science. Here we review 41 farming system design approaches using computer models. Our main findings are the following: (1) the reviewed literature do not make reference to the theoretical approaches from the field of design science. (2) Two categories of farming system approaches can be distinguished: optimisation approaches, and participatory and simulation-based
\end{abstract}

G. Martin $(\bowtie) \cdot$ M. Duru

INRA,

UMR 1248 AGIR,

31326 Castanet Tolosan, France

e-mail: gmartin@toulouse.inra.fr

G. Martin

Crop Science Group, Institute of Crop Science and Resource

Conservation, University of Bonn,

Bonn, Germany

R. Martin-Clouaire

INRA,

UR 875 BIA,

31326 Castanet Tolosan, France approaches. These two categories are connected to two of the main design science theories. (3) For optimisation approaches, farming system design is mainly seen as a problem-solving process. Emphasis is placed on the computational exploration of the solution space by a problem-solving algorithm. (4) For participatory and simulation-based approaches, conceptualization of the design problem is central to the farming system design process. The subsequent exploration of the solution space relies on the creativity of humans. (5) Optimisation approaches, and participatory and simulationbased approaches are oriented towards the development of exploitative rather than exploratory innovations. Exploitative innovations involve the exploitation of available knowledge while exploration innovations build on knowledge created in the course of the design process.

Keywords Problem definition · Problem solving $\cdot$ Reflection in action · Participation · Optimisation - Simulation · Farm model $\cdot$ Innovation

\section{Contents}

1. Introduction. . . . . . . . . . . . . . 2

2. Conceptual and methodological framework. ...... 3

2.1. Theoretical background on design. . . . . . . . 3

2.1.1. What is design?.............. 3

2.1.2. What is design science? .......... 4

2.1.3. The heritage of Herbert Simon. . . . . . . . . 4

2.1.4. Donald Schön's break-away. . . . . . . . . . 4

2.2. Methodological framework. ........... 5

3. Two categories of farming system design approaches. .6 
3.1. Preamble. ..................6 6

3.2. Optimisation approaches. .........6 6 3.2.1. Design context. . . . . . . . . . 6

3.2.2. Design process. . . . . . . . . . . 9

3.2.3. Computer models' structure. . . . . . . . . 9

3.3. Participatory and simulation-based approaches. . 11

3.3.1. Design context. . . . . . . . . . . . . 11

3.3.2. Design process. . . . . . . . . . . . 11

3.3.3. Computer models' structure. . . . . . . . . 12

3.4. Connection and differentiation. . . . . . . . 13

4. Farming system design for what kind of innovations?. .14

5. Research agenda. . . . . . . . . . . 15

6. Conclusion. . . . . . . . . . . . . . . . . 16

7. Acknowledgements. . . . . . . . . . . . . 16

8. References. .................... . 16

\section{Introduction}

Farming systems are faced with complex, dynamic and interrelated changes in the production context related (among other things) to climate change, increasing food demand, scarcity of natural resources, volatile input and output prices, rising energy costs and administrative regulation. The pace, scale and even the direction of such changes are hardly predictable (Thompson and Scoones 2009). Consequently, farming systems and management practices have to be continuously adapted by farmers to this changing world. This continuous adaptation calls for the development of innovations in farming systems (Figs. 1 and 2). Innovation, at the level of an individual farming system, might be defined as the application of ideas that are new to the farming system, whether the new ideas are embodied in products, processes, services, or in work organisation, management or marketing systems (adapted from Schumpeter quoted by OECD 2005). Innovation can involve the creation of entirely new knowledge as well as the diffusion of existing knowledge. In all

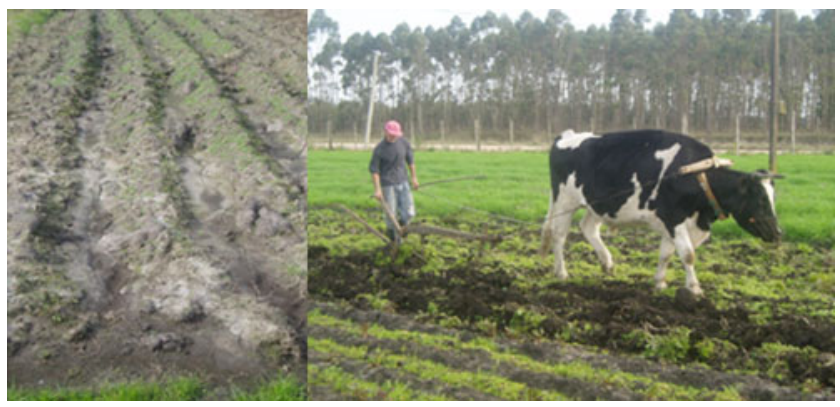

Fig. 1 Conventional vegetable production systems in Uruguay tend to generate environmental side effects such as high soil erosion rates (left picture) that can be drastically reduced through a change towards more sustainable farming involving among various innovations the use of green manure (right picture)

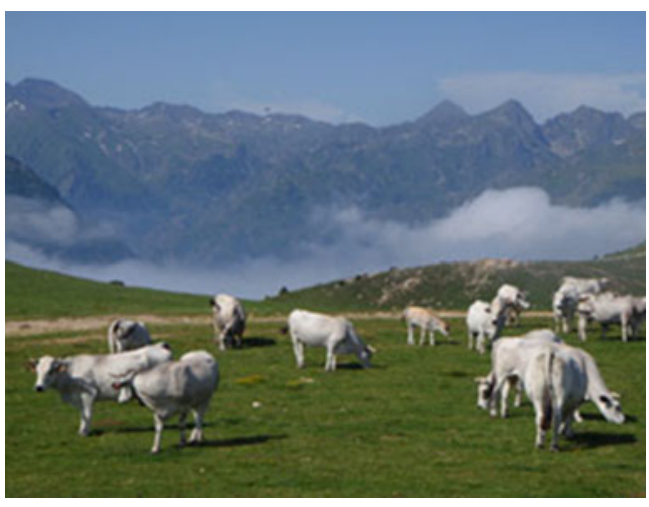

Fig. 2 In south-western France, during summer, farmers increasingly move their livestock to summer pastures located in the Pyrenees Mountains. This innovation (which is actually based on ancestral know-how) is a response to the increasing frequency of unfavourable climatic conditions generating scarcity of herbage available at grazing during summer

cases, introduction of an innovation into a farming system to better cope with the changing world requires the design of an alternative system.

The design of alternative farming systems may yield two kinds of innovation (March 1991) differentiated in two ways: (1) their proximity to existing technologies (cultivars, pesticides, etc.) and management practices (type, timing, intensity, etc.) and (2) their proximity to existing organization of farming systems (structure of internal flows of matter, crop rotations, etc.). Exploitative innovations are incremental innovations designed to improve existing farming systems in order to achieve clearly identified new goals to better cope with the changing world. It involves exploiting available knowledge and skills and expanding existing technologies and management practices without in-depth modification of the organization of farming systems. Adjustment of the timing of farming operations to improve the outputs/inputs ratio of the farms (Martin et al. 2011c) is an example of exploitative innovation. Exploratory innovations are radical innovations designed to meet emerging aspects of the production context or create new production output. It builds on new knowledge created in the course of the design process. It involves a departure from existing technologies and management practices as well as the organization of farming systems through, for example, a change from existing livestock systems with animal feeding mainly based on silage maize to systems adapted to climate change by 2050 with animal feeding based on the combination of a diversity of forage resources (Martin et al. 2011a). Compared with exploitative innovations, the development and implementation of exploratory innovations comes together with changes in the values and goals of the farmer.

For years, the agricultural research community has focused largely on field-scale analytical approaches aimed at improving individual farm management practices, i.e. 
exploitative innovations (Darnhofer et al. 2010). Recently, this research community has been expanding the "farming system design" field of research, as shown by the setting up of "Farming Systems Design" symposiums (Donatelli et al. 2007; Hatfield and Hanson 2009). A variety of quantitative and qualitative design approaches focused mainly on the farm scale have been developed to provide the means to deal with the development of exploitative or exploratory innovations in farming systems. These approaches include diagnosis and prescription (Doré et al. 1997), in situ experimentation (Mueller et al. 2002), the "prototyping" methodology (Vereijken 1997; Rapidel et al. 2009) and participatory approaches such as Reflexive Interactive Design (Bos et al. 2009). The focus of this article is on another type of approach: farming system design with computer models.

Farming system design with computer models refers to design approaches using a computer model at any time in the design process. Basically, computer models consist of a simplified description, i.e. a conceptual model, of the farming system or part of it, as a set of relationships between variables. The variables fall into two groups, controllable and uncontrollable, depending on whether or not they represent factors in the system which can be directly influenced by the actions of the farmer. There are factors which can be measured and used to assess the behaviour of the (virtual) system with respect to performance goals in a given context. A model is used to compute the effect on performance of changes in control variables under certain conditions represented by the uncontrolled variables and by the constraints that convey the structural properties of the system and various laws (physical, moral, regulatory) imposed on it. Once the design problem has been formulated (which is not a straightforward and uniform process), there are in principle many, if not an infinite number, of different values of the controllable variables that match the performance goals. Finding such values, which is the essence of system design, involves intermingling core tasks of analysis, synthesis and evaluation that iteratively yield tentative solutions and appraise their worth with respect to the requirements. The solution to a farming system design problem is a suggested configuration of farm resources (material: land, animals, machinery, etc. and human: labour, etc.) within the system and the farmer's management strategy, i.e. how resources might be allocated over space and time to achieve performance goals. This solution may subsequently be implemented in the field. However, this last step is not the core concern of this article.

So far, with a few exceptions focused on peculiar types of computer models (Janssen and van Ittersum 2007; Bryant and Snow 2008) or on peculiar types of farming (Rossing et al. 2007; Bryant and Snow 2008), the literature has not provided comprehensive assessments for this field of agricultural research.
In addition to providing the state of the art in farming system design with computer models, this article verifies the following two hypotheses:

- The main categories of farming system design approaches (optimization approaches and participatory and simulation-based approaches) do clearly correspond to those already identified in the main design science theories although publications by the farming system community never refer to this theoretical background.

- The main categories of farming system design approaches rarely attempt the development of exploratory innovations despite the acknowledged limitations of exploitative innovations (Ash et al. 2008; Howden et al. 2007) to cope with the changing world context.

Addressing these two points is expected to offer a useful additional perspective to researchers starting a farming system design project making use of computer models.

Amazingly, search requests on ISI Web of Knowledge ${ }^{\mathrm{SM}}$ with the topic "farming system(s) design" led to only four results. Other reviewed publications resulted from search requests aimed at extending the literature sources with expressions such as "farm design", "farm model" and "agricultural system". As we sought coverage of diversity rather than representativeness, we eliminated a number of publications that fell within approaches already represented. For this reason, the analysis is non-exhaustive and finally considers 41 approaches. In section 2, we provide some theoretical background on design and on the two main design science theories. Based on this, a framework for classification and analysis of farming system design approaches making use of computer models is presented. It is then applied to the analysis and comparison of the 41 approaches in section 3 . The contribution of such approaches to the development of exploitative and exploratory innovations (section 4) and research priorities (section 5) is finally discussed.

\section{Conceptual and methodological framework}

\subsection{Theoretical background on design}

\subsubsection{What is design?}

A variety of definitions of design are available in the literature. For instance, some authors consider that "everyone designs who devises courses of action aimed at changing existing situations into preferred ones. The intellectual activity that produces material artefacts is no different fundamentally from the one that prescribes remedies for a sick patient" (Simon 1969). From this perspective, any manager of a system or a process is a "silent" designer (Dumas and 
Mintzberg 1991). Here, we consider a narrower definition in which design is the process of devising a system, component or process that does not yet exist to meet the needs of intended users (Ertas and Jones 1996). Design is ubiquitous in various domains such as architecture, industrial engineering, organisation management or software. A common feature of all these domains is that they deal with how things might be, rather than how they are (Simon 1969). The process requires reconciling what is needed with what is possible. On the one hand, the process of design is driven by some desire or need. On the other, the process of design is constrained by resources - what can be done given the available resources such as time, money, knowledge and skills.

\subsubsection{What is design science?}

Traditionally, design and science were regarded as separate fields. Science was expected to produce knowledge about nature (i.e. the physical world) that could be used to design actions to apply to nature. It is only recently that authors, of which Herbert Simon (see Simon 1969 and subsequent publications to his seminal paper) is the most prominent representative, have started to combine design and science to develop a design science which makes the design process its object of investigation in a domain-independent manner. This was motivated by the fact that "design research does not have a strong relationship with some part of the natural sciences from which research methods and tools may be directly inherited" (Cantamessa 2003). Therefore, more abstract and powerful theories were found to be needed in order to support design processes more efficiently and consistently. Over the years, many attempts to describe design processes have been developed. Two widely acknowledged attempts in the field of design science are described below.

\subsubsection{The heritage of Herbert Simon}

The first generation methods of design methodology in the early 1960 s were heavily influenced by Simon's work (Simon 1969 and subsequent publications). Design is seen as a rational (or rationalizable) process that can be tackled with a problem-solving approach. It consists of the search for a space of possible solutions for the best or at least a satisfactory solution, in a similar way to playing chess or solving crypto-arithmetic problems and puzzles. The word satisfactory refers to the quality of the generated solutions. Due to the excessive size of the real solution space and the impossibility of modelling and exploring it exhaustively, finding an optimal solution is impossible; "good enough" or satisfactory solutions are sought by designers acknowledging their bounded rationality due to the limitations of the information they have, their cognitive capabilities and the time they have to make decisions. Although he recognizes the need for problem definition (which he calls problem setting), Simon does not pay much attention to this difficult task. He focuses on problems assumed to be stable, and defines the solution space that has to be surveyed.

The view of design as a rational problem-solving process has helped, giving much-needed inspiration to design methodology. In Simon's view, design and creativity are special forms of problem solving. Although Simon was critical of maximization theories, he always understood the concept of rationality in one specific case: an empirically based theory of human problem solving, which advocates a form of optimisation ("branch and bound") that operates in a branch of heuristics. This approach is adequate for any design problem that can be tamed enough to lend itself to a reasonable set of goals, criteria, constraints and alternatives that translate into a search space explorable computationally by a problem-solving algorithm such as "branch and bound" or any other optimisation procedure.

This paradigm has been the dominant influence shaping prescriptive and descriptive design methodology ever since. A related approach, called the "systematic design approach", has been developed for engineering design (mechanical design primarily; Pahl and Beitz 1988). The overall design process is broken down into specific design processes for separate functional modules. Each module can then be considered independently with the interactions between them being kept to a minimum. The major advantage of this approach is the simplification of the design process for the individual modules. The systematic design approach aims at facilitating the search for optimum solutions through a set of instructions that constrain the designer to a very high degree. This procedural approach entails a logical sequence, where the initial framing of the problem will still apply during the subsequent stages. What is also implied is some sort of zooming in, that will eventually "tighten" into an optimal solution.

\subsubsection{Donald Schön's break-away}

Donald Schön (1983) strongly criticized the above views, that he called the technical rationality approach. He pointed out that the emphasis on problem solving ignores problem setting, the process by which is defined the ends to be achieved, the decision to be made and the means which may be chosen. In real-world practice, problems do not present themselves to the practitioner as given. They must be constructed from the characteristics of problematic situations: the goals are often unknown when a design project begins, and the requirements and constraints continue to change. In practice, the technical rationality approach can be applied only to well-formed (or assumed so) problems already extracted from practical situations, for which it 
makes sense to optimize a design candidate for known constraints and objectives in terms of a discrete sequence of stages.

Design from Schön's point of view is the activity concerned with the specification of a system defined initially by some partial requirements. Designers cannot have full descriptions of the current problem state, because in principle that would be a full description of the world. They cannot have a list of allowable transformations, because that would presuppose a comprehensive description of the world, and of all worlds reachable from this world. Nor can they have an adequate specification of the goal state, because having that would answer the design problem, reducing it to a construction problem.

By analogy with the practice of professional designers, Schön proposes the Reflection-in-Action paradigm in which designers alternate between framing, making moves, and evaluating moves, because in actual practice, neither problem, nor steps, nor goals can be taken for granted. Framing refers to conceptualizing the problem (i.e. defining objectives) and a move is a (tentative) design decision. Schön's approach is a rather general philosophy that advocates critical thinking in an argumentative participatory process, but it does not include a guide structured in specific steps. It is deployed and enacted in a local situation, where a number of participants produce, or attempt to produce order. The nature of the problem, the goals pursued, the evaluation criteria and the actual steps taken are outcomes of local interactions and sense-making processes within the design group.

\subsection{Methodological framework}

In spite of significant differences, design theories generally rely on similar concepts. Several attempts have been made to organize these common features in an ontology of design science (Gero and Kannengiesser 2008; Hevner et al. 2004). From such efforts, we have retained a number of relevant concepts to build a framework for analyzing the diversity of farming system design approaches making use of computer models. This framework enables the design context, the design process and the structure of computer models used in the course of the design process to be characterized.

The design context sets the scene in which the design process takes place. Characterizing the design context requires specifying what is to be designed, why and for whom. An operand is any entity raising a problem and for this reason being the object of transformations. It can be for instance a plant production system (e.g. cereals, vegetables, fruit), a livestock production system (e.g. dairy cows, pigs, poultry) or a mixed production system. The problem raised by the operand leads to specific design goals which may be agronomic, environmental, economic and/or social. Intended users of the representations of possible solutions to the design problem are humans, e.g. researchers and other stakeholders such as farmers.

Characterizing the design process amounts to analyzing how it is run, following which steps, involving what operator and using which support. The design process can be seen as a sequence of three main activities (Fig. 3), the importance given to each of which depending on the underlying design theory: (a) analysis and conceptualisation of the problem situation, (b) generation and (c) evaluation of a solution. Analysis and conceptualisation of the problem situation involves defining the operand, and assessing the surrounding drivers, constraints and issues. It also requires identifying criteria to describe the current and desired states or performances for the operand, i.e. the design goals. It then amounts to developing a computer model supporting the design process. Generation of a solution consists of exploring the solution space to identify or assemble a potentially suitable solution. Evaluation of this solution amounts to assessing the extent to which the solution identified matches the design goals and constraints. Any design process includes feedback between the three activities (Fig. 3).

The operators contribute to the transformation of the operand by building on their own background knowledge base. This knowledge base includes scientific theories and methods, experiential knowledge of researchers and other stakeholders and expertise about the operand and its possible transformations. Five participation modes of stakeholders are possible (Barreteau et al. 2010): (a) Nil: no participation of stakeholders; (b) Contractual: researchers lead the design process, stakeholders are "contracted" to provide services and support; (c) Consultative: researchers lead the design process but consult and gather information from stakeholders, in particular to integrate their constraints and opportunities and/or priorities; (d) Collaborative: researchers lead the design process but collaborate actively with stakeholders by sharing knowledge throughout this process; (e) Collegiate: researchers and stakeholders work together as colleagues with decisions made by agreement or consensus among all the players.

The design process is supported by the use of artefacts, i.e. material or abstract items created consistently with the operators' knowledge before or during a design process and constituting an interface between researchers and other stakeholders. Among the four types of artefact (constructs, models, methods, instantiations) that can be distinguished (March and Smith 1995 cited by Hevner et al. 2004), we focus on models and more precisely on computer models. Models are abstractions and representations of a real world situation, i.e. the problematic operand or part of it, and possibly of the solution space. Artefacts can best be described by three aspects (Gero and Kannengiesser 2004): (a) Function, i.e. "what the artefact is for" e.g. evaluation of a possible solution; (b) Behaviour, i.e. "how the artefact 
Fig. 3 Main steps included in the three sequences of a generic design process: (a) analysis and conceptualization of the problem situation (white rectangles), (b) generation (grey rectangles) and (c) evaluation of a solution (black rectangles)

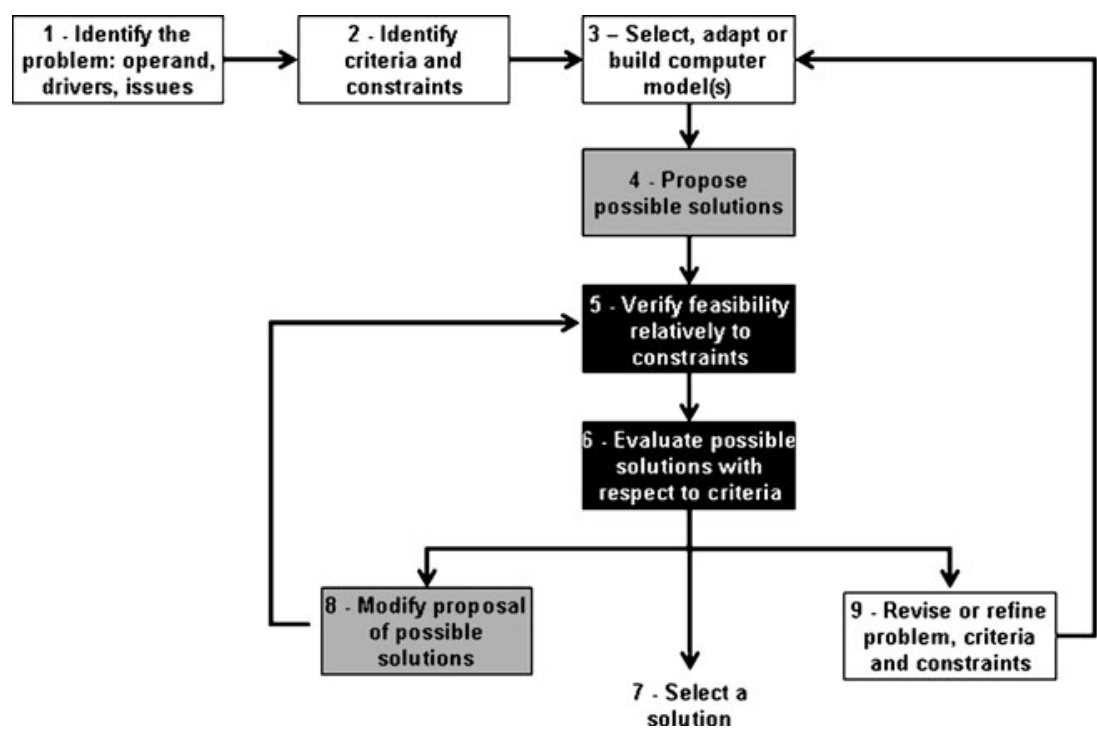

3.2 Optimisation approaches

\subsubsection{Design context}

The reviewed optimisation approaches were applied over a wide range of operands. Mixed farming systems, i.e. mostly dairy cattle systems relying on grasslands and crops, were most represented (Salinas et al. 1999; van Calker et al. 2004). The plant farming systems considered were as diverse as cherries (Cittadini et al. 2008), bulbs (Rossing et al. 1997) and vegetables (Dogliotti et al. 2005). Whereas some of the approaches were confined to a particular type of farming system (Cittadini et al. 2008; Rossing et al. 1997), others were applicable to several types of system, e.g. vegetables, beef cattle and mixed production systems (Dogliotti et al. 2005) or arable, beef and dairy cattle, sheep and goats, and mixed production systems (Louhichi et al. 2010).

In most reviewed approaches, the problem raised by the farming system was very specific and well known, e.g. modification of the common agricultural policy (Veysset et al. 2005), environmental side effects related to high consumption of pesticides and fertilizers (Rossing et al. 1997) or inefficient use of available farm resources (Salinas et al. 1999). In the remaining cases, the nature of the problem remained open and had to be clarified for each application (Bernet et al. 2001; Castelan-Ortega et al. 2003; Groot et al. 2007; Louhichi et al. 2010). Following Simon's view, the problem was assumed to be stable in all cases. The single source of change found did not concern the nature of external drivers but their variability over time, e.g. variability of weather (Cabrera et al. 2006; Flaten and Lien 2007) and of output prices (Mosnier et al. 2009).

Except for one approach (Rossing et al. 2009b), the operators addressed the design problem on the sole basis of their background knowledge, that is, without addition of 


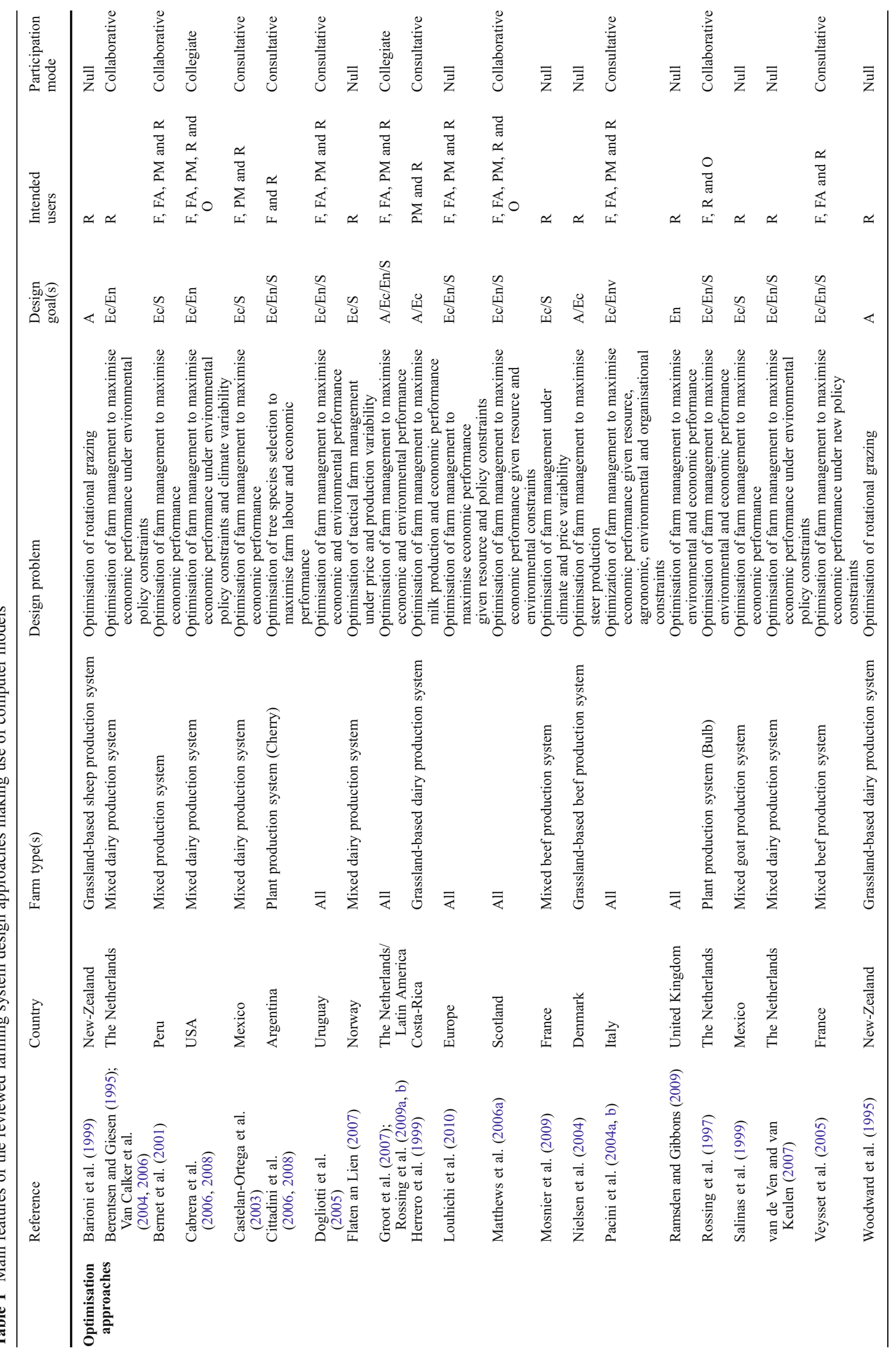




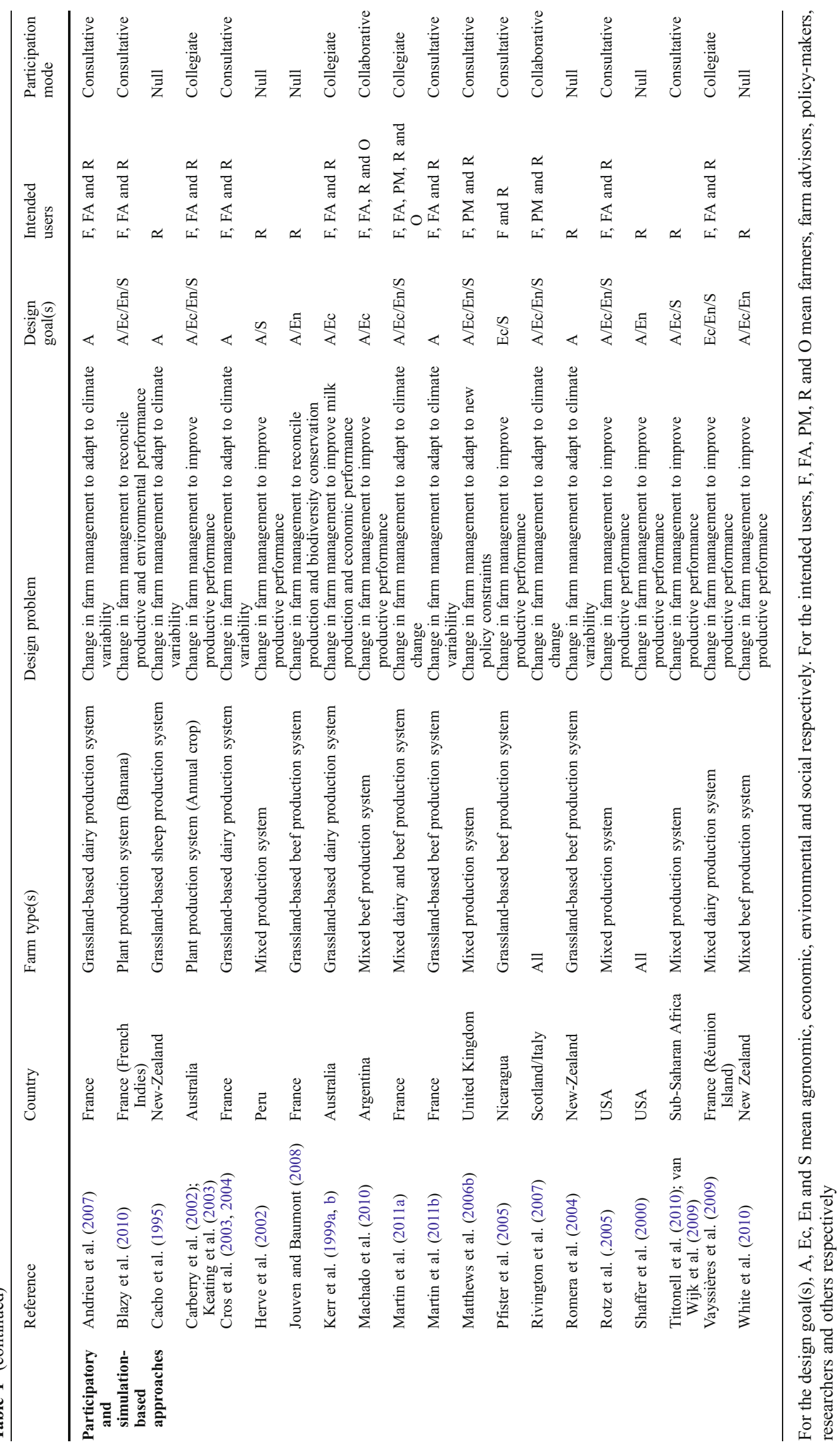


new knowledge either imported or learned during the design process. This problem was in all cases considered to be an optimisation of the configuration of farm resources and their allocation over space and time given farmers' production objectives, constraints, production context (current or modified) and farm resources (current or modified). As a consequence, the definition of the solution space to be explored was determined by the variety of strategic, and in a few cases (Flaten and Lien 2007; Woodward et al. 1995), the tactical decisions considered. For instance, the number of possible crop rotations to be selected for allocation to land units (Dogliotti et al. 2005) or the number of sets of management practices (i.e. a diet and a confinement time for cows and a crop rotation; Cabrera et al. 2006) conditioned the size of the solution space.

The primary concern behind a change in the configuration of farm resources and their allocation over space and time was the improvement of economic performance of existing farming systems. This goal was represented explicitly as a gross margin at the farm scale (Veysset et al. 2005) or per hectare, or implicitly through agronomic factors affecting economic performance, e.g. an improvement of herbage use efficiency at grazing (Woodward et al. 1995). Improvement of economic performance was generally associated with environmental and/or social goals. Environmental goals were clearly formulated regarding, for instance, soil erosion rate (Dogliotti et al. 2005), nitrogen loss, plant species number (Groot et al. 2007) and $\mathrm{CO}_{2}$ emissions (Ramsden and Gibbons 2009). Social goals were not as straightforward but the workload of the farming system designed was often taken into account in the analysis (Cittadini et al. 2008).

Intended users of the representations of farming systems resulting from optimisation varied greatly among the reviewed approaches. In all cases, researchers were primary users of the optimisation results that appeared in scientific publications. In some cases, farmers (Rossing et al. 2009b; Veysset et al. 2005), farm advisors (Bernet et al. 2001), policy-makers (Louhichi et al. 2010; van de Ven and van Keulen 2007) or a range of them (farmers, farm advisors, experts in Cabrera et al. 2008) were other intended users.

\subsubsection{Design process}

There was not much participation of intended users or other stakeholders in the design process. In about half of the reviewed optimisation approaches, there was none (Flaten and Lien 2007; Louhichi et al. 2010; van de Ven and van Keulen 2007). Consequently in most such approaches, and as already observed with Simon's theory, the problem raised by the farming system was assumed to be clear and almost taken for granted (Fig. 4). The decisions to be made, the ends to be achieved and the means chosen were extracted by research on practical situations. The translation of goals, criteria, constraints and alternatives into a solution space was thus carried out by researchers. The three cases of participation during analysis and conceptualization of the problem situation were collaborative, with the involvement of stakeholders during definition of design goals and identification of management constraints (Rossing et al. 1997, 2009b; van Calker et al. 2006).

In line with Simon's theory, most effort was then invested in the problem-solving step, i.e. the generation of a solution by computational exploration of the solution space with problemsolving algorithms (Fig. 4). Such optimisation procedures consisted of the selection of a number of activities (e.g. cropping, grass production for grazing, herd management; Salinas et al. 1999) out of a set defined in an input-output matrix. The development of the set of activities was either performed "by hand" (Berentsen and Giesen 1995) possibly based on consultative participation of stakeholders through farm surveys (Castelan-Ortega et al. 2003) or with computer models (Cittadini et al. 2006). For instance, Dogliotti et al. (2003) developed a crop rotation generator that combines crops from a predefined list to produce all possible rotations, given a number of agronomic filters related, for example, to undesirable crop successions. Quantification of inputs and outputs for each activity used consultative participation of experts (Cittadini et al. 2006; Dogliotti et al. 2004) and computer models. In one case (Cabrera et al. 2008), a collegiate participation of stakeholders was required to adapt these computer models to the design purpose.

Once the input-output matrix of activities was available, the optimisation procedure was run (Fig. 4). While maximising agronomic, economic, environmental and/or social goals once (Cittadini et al. 2008; Louhichi et al. 2010) or several times (Flaten and Lien 2007; Mosnier et al. 2009), problem-solving algorithms selected and allocated activities to a farming system possibly divided into subunits differing, for example in terms of soil type. This optimisation was subject to constraints at the farm level to preserve the consistency of the designed system. For instance, in livestock farming systems, selection and allocation of activities had to consider that feeding requirements had to match onfarm feed production and purchased feed (Berentsen and Giesen 1995; Veysset et al. 2005).

Practical evaluation of the solution identified was rare, as was the possible feedback between problem definition, generation and evaluation of this solution. In two cases only (Rossing et al. 1997, 2009a), the authors reported collaborative participation of stakeholders to discuss the extent to which the solution identified matched the design goals.

\subsubsection{Computer model structure}

Except for Woodward et al. (1995), whose model operated at the grazing system scale, that is the set of grassland fields 
Fig. 4 Respective roles of scientists, stakeholders and of the computer model and their interactions in a farming system design process based on the optimisation approach

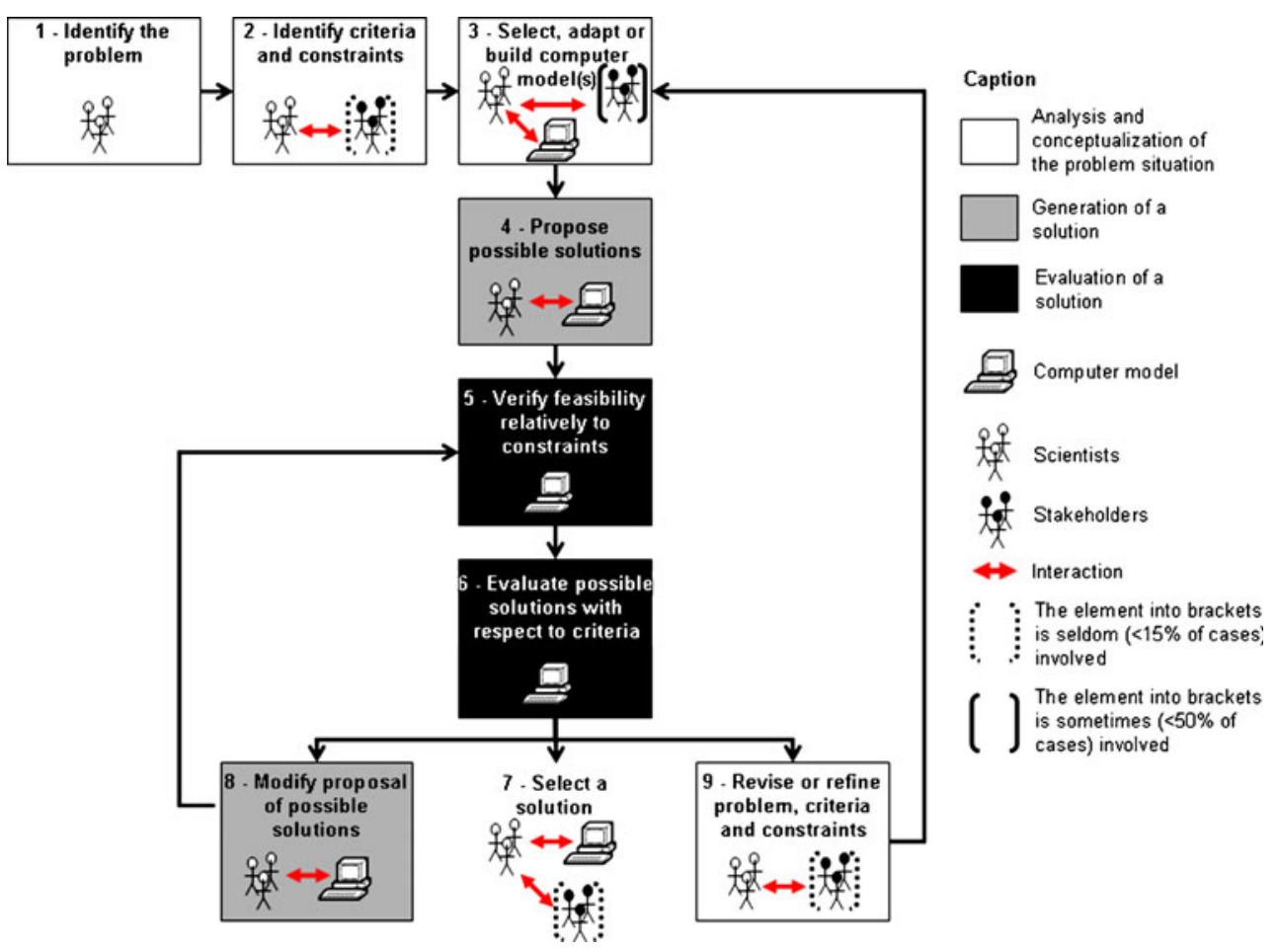

grazed and the grazing animals, optimisation models used for generating alternative farming systems have always operated at the farm scale (Cabrera et al. 2006). The smallest spatial modelling units were so-called land units, i.e. areas of land uniform as regards soil and climatic conditions and the farmer's management practices (Cittadini et al. 2008; Dogliotti et al. 2005; Rossing et al. 1997). In most cases, such land units aggregated several fields. The models of Groot et al. (2007) and Woodward et al. (1995) were the sole optimisation models representing fields individually and even paddocks for the latter. For animals, the smallest modelling unit was an average animal, representative of the herd or a part of it (Bernet et al. 2001; Herrero et al. 1999). At these smallest scales, agricultural activities (crop rotations, temporary or permanent grasslands, dairy cows, etc.; Janssen and van Ittersum 2007) were described by technical coefficients defining the amount of inputs required to achieve a certain level of outputs (agronomic, environmental, economic and/or social; van Ittersum and Rabbinge 1997).

Input-output combinations were calculated from mechanistic and empirical crop, grassland and animal models operating on a daily time step (Castelan-Ortega et al. 2003; Louhichi et al. 2010; Mosnier et al. 2009), or alternatively deduced from experiments (Nielsen et al. 2004; van de Ven and van Keulen 2007), farm data (Veysset et al. 2005) or expert knowledge (Cittadini et al. 2008; Dogliotti et al. 2005), especially when innovative or poorly informed alternatives to the current agricultural activities were considered. At the farm scale, most reviewed optimisation models were static. In such cases, for instance in the case of crop rotations, technical coefficients used as inputs to the optimisation models were averages of input-output combinations over several years. The remaining models were dynamic optimisation models (Cabrera et al. 2006; Mosnier et al. 2009) proceeding in a succession of optimisation rounds, often with time steps of 1 month. This meant that every month, technical coefficients were updated to proceed to the next round of optimisation. In such cases, the time horizon of the models ranged from one (Flaten and Lien 2007) to several (Mosnier et al. 2009) years. Consequently, while models operating over 1 year considered weather as the single variable environmental factor affecting the behaviour of the modelled system (Woodward et al. 1995), models operating over several years also included market conditions (Mosnier et al. 2009).

With the exception of the model of Woodward et al. (1995) which seeks to maximise animal intake at grazing, all the reviewed models allocated agricultural activities to maximize economic return under constraints related, among other things, to farm resources, environmental performance (soil erosion, soil organic matter depletion, nitrogen leaching, etc.), and overall consistency of the system. Farm management was always treated as an optimisation summarized in an objective function. The optimisation procedure was performed using various mathematical techniques, i.e. linear programming (Dogliotti et al. 2005), stochastic programming (Flaten and Lien 2007), dynamic recursive optimisation (Mosnier et al. 2009), branch and bound optimisation (Cabrera et al. 2006) and multi-objective genetic algorithms (Matthews et al. 2006a). 


\subsection{Participatory and simulation-based approaches}

\subsubsection{Design context}

As with optimisation approaches, operands of the reviewed participatory and simulation-based approaches were mostly livestock farming systems. These were either grasslandbased beef or dairy cattle farming systems (Andrieu et al. 2007; Cacho et al. 1995; Romera et al. 2004) or mixed beef and dairy cattle farming systems relying on grasslands and crops (Rotz et al. 2009; Vayssières et al. 2009). Smallholder mixed-farming systems included more marginal crops and livestock species such as quinoa, beans and donkeys (Herve et al. 2002; Pfister et al. 2005). Applications to plant farming systems considered banana (Blazy et al. 2010) and arable crops (Keating et al. 2003).

With participatory and simulation-based approaches the problem raised by the farming system was not always clearly formulated in the scientific articles. Exceptions concerned for instance adaptation to the CAP reform (Matthews et al. 2006b), biodiversity conservation (Jouven and Baumont 2008) and instability of production due to variability of environmental factors such as weather (Martin et al. 2011b; Romera et al. 2004). Two reasons explain this loose formulation of the design problem. First, few approaches (Rivington et al. 2007) addressed design problems considering long term horizon. In such cases, in line with Schön's theory, uncertainty about the problem situation is high. Second, most reviewed articles focused on the computer models used in the course of the design process. The function, behaviour and structure of these models were then presented in details at the expense of the wider design context and problem situation specific to a given application. A problem pointed out by most participatory and simulation-based approaches was the need to improve the understanding of farming systems, their dynamics and internal interactions in particular (Cacho et al. 1995; Keating et al. 2003).

In most cases, the background knowledge of the operators did not change much during the design process. However, in contrast with the optimisation approach, a significant part of the knowledge remained in the mind of the operators and was applied only during the design process instead of being incorporated in the computer model. Still, approaches focused on long-term problems had no preconceived idea about solutions. Changes in the configuration of farm resources and their allocation over space and time by farmers at the strategic, tactical and/or operational levels were then explored. For instance, Kerr et al. (1999a, b) examined changes in land use affecting the whole farming system while Cros et al. (2004) mainly dealt with tactical and operational changes in the feeding and grazing management of dairy cows. One noticeable difference with optimisation approaches is that the reviewed articles (Pfister et al. 2005; van Wijk et al. 2009) pointed to the need to improve our understanding of current farming systems to seek for relevant solutions to their problems. For instance, it was felt necessary to characterize the impact of climate change on farming systems before tackling the identification of possible adaptation strategies (Rivington et al. 2007; Martin et al. 2011a).

The reviewed approaches mostly aimed at improving the agronomic performance of the farming systems. The corresponding goals were yields (Keating et al. 2003; Tittonell et al. 2010) or herbage use efficiency at grazing (Andrieu et al. 2007; Romera et al. 2004). In some cases, multiple goals were examined. Economic performance was assessed for instance with a net margin per hectare (Blazy et al. 2010). Environmental goals for instance included grassland biodiversity (Jouven and Baumont 2008), pesticide use (Blazy et al. 2010) and greenhouse gas emissions (White et al. 2010). Social goals focused on the workload to ensure the feasibility of the farming systems designed (Herve et al. 2002; Martin et al. 2011b).

Again, intended users of the representations of alternative farming systems produced were in all cases researchers as users of such representations for publishing their findings. Farmers (Vayssières et al. 2009), farm advisors (Martin et al. 2011b), teachers (Machado et al. 2010) or a range of them (farmers, bank managers, loan officers and farm advisors in Kerr et al. 1999a, b) were also involved in the design process.

\subsubsection{Design process}

Participation of stakeholders in the design process was much greater with participatory and simulation-based approaches. It was nil for only 6 over the 20 approaches considered. Thus from the very early stages of the design process, stakeholders were involved in analysing the problem situation (Fig. 5). The most extreme case was Vayssières et al. (2009) where the main researcher was immersed in the daily life of farmers and participated in the farming activities in order to gain credibility in the eyes of farmers and to assess with them what were their most critical problems. Carberry et al. (2002) pursued the same objective with a collegiate participation as well. This position follows Schön's point of view, as the invitation for stakeholders' participation indicates that researchers consider they do not have adequate descriptions of the problem, of perceived solutions and goals and of the promising farming systems reachable from the current farming systems. In addition, computer models were used at this stage in a few of the reviewed approaches (Martin et al. 2011a; Rivington et al. 2007). They enabled problem situation analysis to characterize the exposure and vulnerability of farming 
Fig. 5 Respective roles of scientists, stakeholders and of the computer model and their interactions in a farming system design process based on the participatory and simulationbased approach

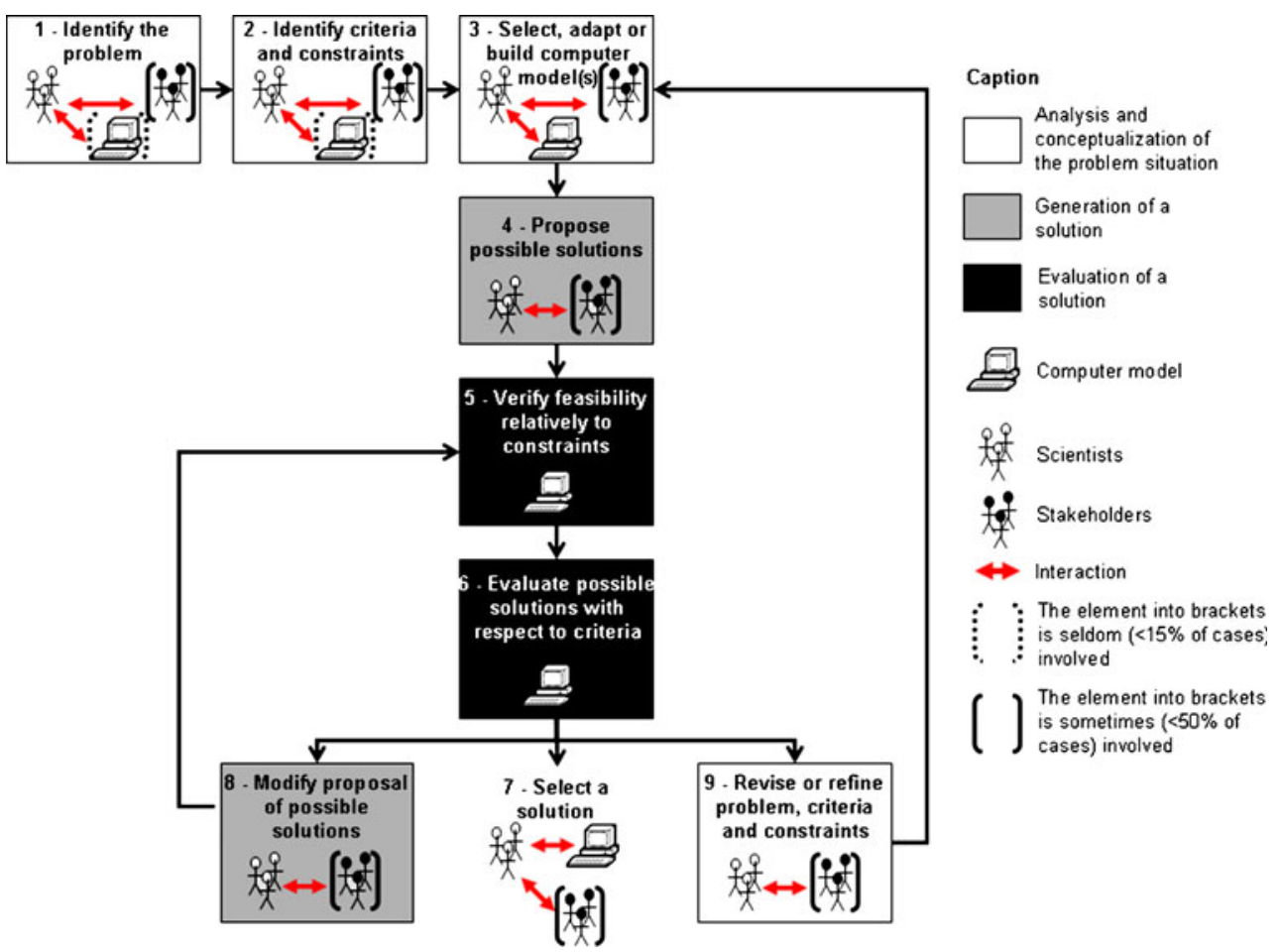

systems to climate change. Climate models and crop and grassland models were used to characterize the local impact of climate change on crop and grassland production.

In contrast to optimisation approaches, exploration of the solution space to generate a solution relied on the creativity of researchers and involved stakeholders (Fig. 5). As with Schön's Reflection-in-Action paradigm, this exploration consisted of identifying "by hand" an initial possible solution and in defining contextualised simulation experiments, possibly through collegiate participation (Carberry et al. 2002; Martin et al. 2011a; Matthews et al. 2006a) to evaluate the relevance of this solution in order to return to the problem definition and to correct the initial solution. At this stage, computer models could be used to develop specific artefacts supporting the design process (Fig. 5). For instance, Martin et al. (2011a) have developed flattened wooden sticks (that they call forage sticks) marked with the forage yield in kilograms per hectare and per 4-week period across the calendar year for a number of forage crop including new crops in the area, and its year-round management (e.g. early and productive permanent grassland grazed six times a year) including novel practices. During participatory workshops, players had to select sticks and to assign an area to each selected stick as a first step towards the design of a whole livestock production system. Such forage sticks have been built using crop and grassland models.

Using a computer model (Fig. 5), evaluation of alternative farming systems was conducted through virtual experimentation, reproducing their behaviour over a given period and under different production contexts (Romera et al. 2004;
Vayssières et al. 2009). For instance, in Martin et al. (2011a), after players had selected forage sticks and assigned an area to each selected stick, they used a balance model to evaluate whether forage production in the assemblage created by the players would match animal feeding requirements. On the basis of the output, players were invited to reconsider their tentative solution (Fig. 5). The evaluation stage also enabled consultative participation of farmers through discussions about the relevance and feasibility of alternative farming systems (Martin et al. 2011b).

Throughout the design and evaluation loops, the model user(s) and involved stakeholders proceeded empirically by trial and error to explore the solution space and progressively elaborate a satisfactory solution that achieved the desired goals whilst satisfying constraints (Fig. 5). For instance, Carberry et al. (2002) described the behaviour of farmers exploring their own system and learning through the use of a computer model, rather like "learning by doing". Similar observations are reported in Duru and Martin-Clouaire (2011).

\subsubsection{Computer model structure}

The mechanistic computer models used for problem situation analysis simulated dynamically crop and grassland production at the field scale on a daily time step and over a single production cycle (Martin et al. 2011a; Rivington et al. 2007). The single environmental factor considered was weather, to characterize the local impact of climate change on crops and grasslands. Such models focused mainly on biophysical aspects, with detailed representations of the soil 
and crop/grassland components of the field. However, most of them paid little attention to the representation of farmers' decision-making processes. In the simplest case, farm management was seen as a sequence of technical actions on fixed dates as simulation inputs (Stöckle et al. 2003 used in Rivington et al. 2007). A more elaborate representation, i.e. the rule-based approach, was used in Martin et al. (2011a). It relates the decisions made and related actions to conditions encountered dynamically. The computer models used for problem situation analysis thus corresponded to so-called crop and grassland models.

Simulation models enabling evaluation of alternative farming systems all operated at the farm scale (Jouven and Baumont 2008; Shaffer et al. 2000), except for a grazing system model (Cros et al. 2003). The smallest spatial modelling unit was generally a field (Romera et al. 2004; Pfister et al. 2005). In a few cases, it was the so-called land unit, possibly aggregating several fields (Blazy et al. 2010; Herve et al. 2002) and in one case, the whole farm was treated as if it was a single paddock of pasture (White et al. 2010). Animal processes were modelled at the scale of individual cows (Romera et al. 2004), of average representative animals (Andrieu et al. 2007; Martin et al. 2011b), of the whole herd (White et al. 2010).

The biophysical models integrated within the farm models were either mechanistic (Keating et al. 2003; Shaffer et al. 2000), statistical (Herve et al. 2002; Pfister et al. 2005), mechanistic and statistical (Cacho et al. 1995; Kerr et al. 1999a, b) or mechanistic and empirical (Martin et al. 2011b). The biophysical models were either static (White et al. 2010) or dynamic, operating on a time step of 1 year (Kerr et al. 1999a, b), 1 week (Blazy et al. 2010) or 1 day (Keating et al. 2003), even when the related farm model was static (Martin et al. 2011a). The remaining dynamic farm models had a time horizon ranging from one season (Cros et al. 2003) to several years (Blazy et al. 2010; Cacho et al. 1995). Weather was the main environmental factor influencing the behaviour of the modelled system (Andrieu et al. 2007), but market conditions and policy context were considered in some cases (Blazy et al. 2010; Matthews et al. 2006b).

Farm management was generally modelled with rulebased systems (Cros et al. 2003). However, this approach offers no powerful means to create links between rules so as to control the order in which they are used. Hence Martin et al. (2011b) used a recent and more sophisticated approach (Martin-Clouaire and Rellier 2009) called activity-based models, in which management is seen as the problem of coordinating activities because these require resources which are either limited or constrained by availability over time and also because future activities need to be anticipated in relation to present ones. Instead of using rules, management is thus represented as a set of activities organised in plans that are flexible and adaptable to changing conditions.
In contrast, a few models neglect the dynamics of farm management by assuming fixed strategic and tactical decisions defined as inputs (Kerr et al. 1999a, b; Pfister et al. 2005). Mathematical techniques used to integrate the behaviour of the simulated system ranged from continuous time simulation (Shaffer et al. 2000), to discrete event simulation (Martin et al. 2011b), stock-flow simulation (Pfister et al. 2005; Vayssières et al. 2009), spreadsheet models consisting of static balances (Martin et al. 2011a) and a combination of static models (White et al. 2010).

\subsection{Connection and differentiation}

Clearly the optimisation approach corresponds to Simon's problem-solving theory. The participatory and simulationbased approach shares with Schön's theory the emphasis on the key roles played by stakeholders' participation and tacit knowledge. Because Schön's theory provides principles rather than practical methods, it does not give a specific status to simulation. The fundamental differences between Simon's and Schön's theories remained when comparing the two approaches used in farming system design. These differences were concerned with several aspects including the importance given to each step of the design process, the participation of stakeholders to this process, the function, behaviour and structure of the computer models used, and the type of interactions between the model and the stakeholders involved (Figs. 4 and 5).

With the optimisation approach, the computer model includes (a) a representation of the relations (constraints) that the system to be designed (e.g. a farm) should satisfy and (b) the aggregated criteria that enable one to discriminate between several potential design solutions. In the participatory and simulation-based approach, the computer model represents only what the system to be designed is composed of and how these components interact dynamically with the external environments of the system and internally between them. In the participatory and simulationbased approach, the criteria are not formalized; they remain in the heads of the operators, who may have different values and preferences.

In the optimisation approach, the computer model of the system is typically static (a set of algebraic equations in which time is not explicitly represented) whereas in the participatory and simulation-based approach, the computer model of the system is dynamic and responsive to external factors, e.g. weather. Dynamic models keep changing with reference to time whereas static models are at equilibrium in a steady state; the equilibrium might change but not necessarily in relation to a notion of time advancing.

In the optimisation approach, the computer model of the system is essentially a constraint enforcement framework that fully delimits the solution space. In the participatory 
and simulation-based approach, the computer model is not imposing such a strong restriction on the solution space. In addition, the operators have much more freedom to change the computer model than with the optimisation approach because the latter requires computer models that should be simple enough in order to remain computationally tractable by the optimisation algorithm.

The modelling effort in the optimisation approach is different than in the participatory and simulation-based approach because the representation is done at a very abstract level (e.g. numerical variables linked by linear equations) required by the optimisation algorithm. Consequently modifying the computer model in the design process requires a highly technical competence and operators that do not possess it cannot contribute. In the participatory and simulationbased approach, the mapping between reality and representation is more direct (the concepts used to characterise the reality have their direct counterpart in the simulation model). For this reason, it is much easier for the operators to pinpoint the reasons for particular behaviour of the computer model (causality can be traced) and to suggest changes to the computer model (i.e. changes to the model of the system to be designed).

Finally, the optimisation approach and participatory and simulation-based approach differ in their merits and limitations: the optimisation approach takes advantage of the computational power of machines to explore efficiently a large solution space, the main limitation coming from representation restriction imposed by the optimisation machinery. The participatory and simulation-based approach emphasises temporal-based thinking, that is, thinking about how the system and its environment may evolve over time, which makes it possible to evaluate situational decisionmaking options. In the participatory and simulation-based approach, the main limitation relates to the absence of optimisation: a much better solution might lie not very far from the one produced by the participatory and simulationbased approach.

In spite of the above differences, the reasons for choosing one particular approach over another are seldom addressed in the scientific literature. Apart from the author(s)' allegiance to a particular scientific community and its idiosyncrasies, one could relate this choice to the applications considered, which can best be described by the design context and by the nature of the innovations developed for farming systems to cope with the changing world. If differences in problem formulation were evident, the nature of the problems tackled, the kind of decisions taken by intended users (e.g. national vs. on-farm policy) and the wider design context were in the end not fundamentally different. The nature of the innovations generated by the two categories of farming system design approaches making use of computer models is further analysed in the next subsection.
4 Farming system design for what kind of innovations?

Most of the reviewed optimisation-based and participatory and simulation-based approaches supported the development of exploitative innovations. For instance, Dogliotti et al. (2005) supported the introduction of crop rotations in farming systems practicing monocropping. This process involved a revision of the whole farming system but it built upon knowledge available to the operators that was integrated into several technical coefficient generators and an optimisation model. Similarly, Martin et al. (2011b) described the adaptation of grassland-based beef cattle systems into more flexible ones, i.e. with a configuration and management dictated by weather conditions and the ongoing system state. This process involved major changes in land use (area for grazing vs. for mechanized harvest) and grassland use (type, timing and intensity) but it relied on well-established scientific and empirical knowledge.

The merits and limitations of each category of approach supporting the development of exploitative innovations have never been analysed. It seems evident that the main difficulty with optimisation-based approaches regards the formulation of the problem, and in particular the criteria upon which the optimisation relies. These criteria need to be consistent with the concerns of intended users in order to support exploitative innovations and with the kind of information provided by the computer model. With participatory and simulation-based approaches, the design process consists of the progressive modification of a solution throughout design and evaluation loops in order to yield a satisfactory solution. Much room is given to the incorporation of new knowledge and ideas in the design process but the main difficulty is to start with a solution that is good enough as it conditions the solution finally retained and obtained by incremental correction of the initial one.

Only three approaches (Martin et al. 2011a; Rivington et al. 2007; Rossing et al. 2009b) contributed to develop exploratory innovations yet these may be required to cope effectively with the changing world (Ash et al. 2008; Howden et al. 2007). These were optimisation-based and participatory and simulation-based approaches relying on high levels of stakeholder participation. These approaches used computer models during problem situation analysis, generation and evaluation of possible solutions to stimulate discussions between participants. For instance, with the collegiate participation of farmers, Martin et al. (2011a) developed alternatives to the current dairy farms adapted to the long-term consequences of climate change. This design process was challenged by the uncertainty about the problem situation. Simulations at the component (grassland, animal) scale were conducted and presented during workshops. Indeed, interactions between the components of the studied system might not remain the same with climate 
change. In the end, the alternatives to the current dairy farms exhibited major changes in the number and types of forage crops grown and in the management of the herds.

One of the main limitations of this kind of approach is that the development of innovations depends on the social relations between the operators and their ability to communicate and share knowledge (Voinov and Bousquet 2010). Another relates to the uncertainty about the problem situation, which could lead to vague problem definitions and to the production of inadequate innovations. The solution space to be explored is definitely larger than with exploitative innovations. Hence starting the design process with a clear enough solution is an even more acute difficulty.

A possible reason for this imbalance between approaches favouring exploitative and exploratory innovations relates to the format of scientific publications in the field of agricultural science. With exploitative innovations, as sufficient data are generally available, calibration and validation of computer models used in the course of the design process rely on statistical approaches that are well accepted by the agricultural science community. When it comes to exploratory innovations, calibration and validation are mostly based on common sense knowledge of the operators. This approach is not yet common in the field of agricultural science. Therefore, authors might give in to the temptation of supporting the development of exploitative innovations that can be more easily published. A similar observation has been reported by Prost et al. (2011). These authors have pointed out that there are a number of standardized steps in the development of agronomic models. The order and content of these steps are never adapted to the intended use of the model. Indeed, acknowledging these steps is an efficient way to communicate and publish the agronomic models even if it might not be the most appropriate way to achieve the intended use of the model.

Prost et al. (2011) have observed that if the use of agronomic models for action is often claimed by researchers, this use is not very well established. Similarly, if farming system design processes often aim at solving practical problems, implementation of the innovations developed in the course of farming system design processes is seldom addressed in the reviewed articles. This is related partly to the problem of implementation (McCown 2002), i.e. to the many obstacles that may exist between a solution to the design problem identified with a computer model and the reality of practice, for example supply chains unable to integrate alternative farming systems introducing exploratory innovations. On the other hand, with approaches displaying a high level of participation, one would expect more practical applications following the design process. Instead, it seems that authors of such approaches sometimes use farm advisors' and farmers' knowledge for research speculations (and publications). However this is not always the case. For instance, the FARMSTEPS approach (Groot et al. 2007; Rossing et al. 2009a, b) pays particular attention to shaping co-innovation between researchers and farmers.

\section{Research agenda}

As already stated, the reviewed publications do not refer to the theoretical approaches from design science. Concretising this connection would favour theoretical and methodological importation in farming system design approaches making use of computer models. Indeed, such approaches are developed independently and little effort has been devoted to synthesize the various experiences into a number of relevant concepts and methodological guidelines. Yet, based on this literature review, it seems clear that there are promising opportunities to benefit from each category of approach as they have focused on specific and different stages of the design process, i.e. generation of a solution for optimisation and problem situation analysis and evaluation of a solution for participatory and simulation-based approaches. Again, insights from design science can support this process. In the early 2000s, a new design theory, C-K design theory, developed by Hatchuel and Weil (2003) was proposed. Its most original feature is that it expands Simon's approach and proposes to enable the use of the problem-solving paradigm in a dynamically-constructed design problem by giving much more room to creativity in the design process, as advocated by Schön. Hence it constitutes a third theory which reunifies the positive aspects of both Simon's and Schön's theories.

The function of computer models in the course of farming system design processes and their corresponding behaviour and structure has to be better articulated. In particular, the appropriate level of detail of the computer models to be used for a given design context remains a key question seldom addressed in the literature. In most cases, a computer model is used because it is already available. Alternatively, it is built upon researchers' knowledge but the scientific reasons for selecting a given level of detail are poorly justified. Yet it might have an influence on the design process by focusing the attention of operators on particular points for which the model being used is very detailed. A methodology is lacking to support the analysis of the appropriate level of detail to be included in these models. Sensitivity analysis of computer models to various levels of detail (Adam et al. 2010) has provided promising results toward this end.

The optimisation-oriented approaches could potentially be improved by incorporating the important developments made in constraint programming (Rossi et al. 2006; Benhamou et al. 2007) that provides new efficient means to address combinatorial problems such as farming system design problems. Constraint programming offers an orthogonal 
but complementary approach to classical techniques from mathematical programming (e.g. linear programming) or stochastic optimisation techniques (e.g. simulated annealing, genetic algorithms or tabu search).

Another development needed to strengthen farming system design processes making use of computer models concerns the methodology of participatory research. Stakeholder participation is increasingly being used (Voinov and Bousquet 2010) as it favours a broader and more balanced view of issues by bringing together several people having different backgrounds and skills. Participatory approaches are also appreciated as another way of dealing with agricultural innovation which is no longer regarded as a simple linear process, wherein agricultural research and development creates technologies that are transferred via advisors to farmers. Instead, agricultural innovation is recognised as "a complex, interactive process" of co-learning and negotiation (Klerkx et al. 2010). At the moment, guidelines for good practices with participation exist (Douthwaite et al. 2008) but remain insufficiently applied in the field of agricultural science. Formalized participatory design approaches that are not supported by computer models exist (Bos et al. 2009) and can constitute another insightful source of inspiration in addition to crossdisciplinary research involving researchers from social science.

Evaluation of farming system design approaches is another research priority. Whereas the outputs (in the form of knowledge embodied in peer-reviewed articles, software or datasets) of a design project are easily traceable, the outcomes (changes in values, attitudes and behaviour in the world beyond the walls of the research institute; Matthews et al. 2011) are seldom analysed (Pacini et al. 2004a, b), partly because of the limited literature for their formal evaluation (Weersink et al. 2002). Yet design is an applied activity and the support of social scientists is required to evaluate, and if necessary improve, the extent to which farming system design processes affect the intended users of their products, and whether or not these products are made use of.

\section{Conclusion}

In order to offer a useful additional perspective to researchers starting such a farming system design project making use of computer models, we have reviewed 41 such approaches. Two categories of farming system design approaches can be distinguished: optimisation approaches and participatory and simulation-based approaches. Although not acknowledged by their authors, they are connected to two of the main design science theories. With optimisation approaches, emphasis is placed on the exhaustive computational exploration of the solution space by a problem-solving algorithm.
With participatory and simulation-based approaches, emphasis is placed on problem situation analysis and exploration of the solution space relies on the creativity of humans. Differences regarding for instance the structure of the computer models used in the course of the design process were evident between the two kinds of approach. However both were aimed at the development of exploitative rather than exploratory innovations yet the latter are considered to be required to cope with the changing world. Theoretical and methodological developments are needed to strengthen this field of agricultural science and to support the development of relevant and credible exploratory innovations to create farming systems to better cope with the changing world.

Acknowledgements This work has been funded by the Alexander von Humboldt Foundation and by the French ANR SYSTERRA program as part of the project O2LA (Organismes et Organisations Localement Adaptés, ANR-09-STRA-09). The authors thank the anonymous reviewers and the field editor for thier constructive comments.

Open Access This article is distributed under the terms of the Creative Commons Attribution Noncommercial License which permits any noncommercial use, distribution, and reproduction in any medium, provided the original author(s) and source are credited.

\section{References}

Adam M, Van Bussel LGJ, Leffelaar PA, Van Keulen H, Ewert F (2010) Effects of modelling detail on simulated potential crop yields under a wide range of climatic conditions. Ecol Modell 222:131-143

Andrieu N, Poix C, Josien E, Duru M (2007) Simulation of forage management strategies considering farm-level land diversity: Example of dairy farms in the Auvergne. Comp Elec Agr 55:36-48

Ash A, Nelson R, Howden M, Crimp S (2008) Australian agriculture adapting to climate change: balancing incremental innovation and transformational change. Proceedings of the ABARE Outlook 2008 Conference, Canberra, http://pandora.nla.gov.au/pan/ 45562/20081028-0951/www.abare.gov.au/interactive/Outlook08/ files/day_1/Ash_ClimateChange.pdf [accessed 28 Nov 2011]

Barioni LG, Dake CKG, Parker WJ (1999) Optimizing rotational grazing in sheep management systems. Environ Int 25:819-825

Barreteau O, Bots PWG, Daniell KA (2010) A framework for clarifying "participation" in participatory research to prevent its rejection for the wrong reasons. Ecol Soc 15(2):1

Benhamou F, Jussien N, O'Sullivan B (2007) Trends in constraint programming. Wiley, London

Berentsen PBM, Giesen GWJ (1995) An environmental-economic model at farm-level to analyze institutional and technical change in dairy farming. Agr Syst 49:153-175

Bernet T, Ortiz O, Estrada RD, Quiroz R, Swinton SM (2001) Tailoring agricultural extension to different production contexts: a userfriendly farm-household model to improve decision-making for participatory research. Agr Syst 69:183-198

Blazy JM, Tixier P, Thomas A, Ozier-Lafontaine H, Salmon F, Wery J (2010) BANAD: a farm model for ex ante assessment of agroecological innovations and its application to banana farms in Guadeloupe. Agr Syst 103:221-232 
Bos AP, Groot Koerkamp PWG, Gosselink JMJ, Bokma S (2009) Reflexive interactive design and its application in a project on sustainable dairy husbandry systems. Outlook Agr 38:137-145

Bryant JR, Snow VO (2008) Modelling pastoral farm agro-ecosystems: a review. New Zeal J Agr Res 51:349-363

Cabrera VE, Hildebrand PE, Jones JW, Letson D, de Vries A (2006) An integrated North Florida dairy farm model to reduce environmental impacts under seasonal climate variability. Agric Ecosyst Environ 113:82-97

Cabrera VE, Breuer NE, Hildebrand PE (2008) Participatory modeling in dairy farm systems: a method for building consensual environmental sustainability using seasonal climate forecasts. Clim Chang 89:395-409

Cacho OJ, Finlayson JD, Bywater AC (1995) A simulation model of grazing sheep. II - whole farm model. Agr Syst 48:27-50

Cantamessa M (2003) An empirical perspective upon design research. J Eng Des 14(1):1-15

Carberry PS, Hochman Z, McCown RL, Dalgliesh NP, Foale MA, Poulton PL, Hargreaves JNG, Hargreaves DMG, Cawthray S, Hillcoat N, Robertson MJ (2002) The FARMSCAPE approach to decision support: farmers', advisers', researchers' monitoring, simulation, communication and performance evaluation. Agr Syst 74:141-177

Castelan-Ortega OA, Fawcett RH, Arriaga-Jordan C, Herrero M (2003) A decision support system for smallholder campesino maize-cattle production systems of the Toluca Valley in Central Mexico. Part I - Integrating biological and socio-economic models into a holistic system. Agr Syst 75:1-21

Cittadini ED, van Keulen H, Peri PL (2006) FRUPAT: a tool to quantify inputs and outputs of patagonian fruit production systems. Acta Hortic 707:223-230

Cittadini ED, Lubbers MTMH, de Ridder N, van Keulen H, Claassen GDH (2008) Exploring options for farm-level strategic and tactical decision-making in fruit production systems of South Patagonia, Argentina. Agr Syst 98:189-198

Cros MJ, Duru M, Garcia F, Martin-Clouaire R (2003) A biophysical dairy farm model to evaluate rotational grazing management strategies. Agronomie 23:105-122

Cros MJ, Duru M, Garcia F, Martin-Clouaire R (2004) Simulating management strategies: the rotational grazing example. Agr Syst 80:23-42

Darnhofer I, Bellon S, Dedieu B, Milestad R (2010) Adaptiveness to enhance the sustainability of farming systems. A review. Agron Sustain Dev 30:545-555

Dogliotti S, Rossing WAH, van Ittersum MK (2003) ROTAT, a tool for systematically generating crop rotations. Eur J Agr 19:239-250

Dogliotti S, Rossing WAH, van Ittersum MK (2004) Systematic design and evaluation of crop rotations enhancing soil conservation, soil fertility and farm income: a case study for vegetable farms in South Uruguay. Agr Syst 80:277-302

Dogliotti S, van Ittersum MK, Rossing WAH (2005) A method for exploring sustainable development options at farm scale: a case study for vegetable farms in South Uruguay. Agr Syst 86:29-51

Donatelli M, Hatfield JL, Rizzoli A (eds) (2007) Proceedings of Farming Systems Design 2007, Catania (Italy), 10-12 September $2007,478 \mathrm{p}$

Doré T, Sebillotte M, Meynard JM (1997) A diagnostic method for assessing regional variations in crop yield. Agr Syst 54:169-188

Douthwaite B, Alvarez BS, Cook S, Davies R, George P, Howell J, Mackay R, Rubiano J (2008) Participatory impact pathways analysis: a practical application of program theory in research-fordevelopment. Can J Program Eval 22:127-159

Dumas A, Mintzberg H (1991) Managing the form, function, and fit of design. Des Manag J 2(3):26-31

Duru M, Martin-Clouaire R (2011) Cognitive tools to support learning about farming system management: a case study in grazing systems. Crop Pasture Sci 62:790-802
Ertas A, Jones J (1996) The engineering design process, 2nd edn. New York, N.Y., John Wiley \& Sons, Inc

Flaten O, Lien G (2007) Stochastic utility-efficient programming of organic dairy farms. Eur J Oper Res 181:1574-1583

Gero JS, Kannengiesser U (2004) The situated function-behaviourstructure framework. Des Stud 25(4):373-391

Gero JS, Kannengiesser U (2008) An ontological account of Donald Schön's reflection in designing. Int J Des Sci Tech 15(2):77-90

Groot JCJ, Rossing WAH, Stobbelaar DJ, Renting H, van Ittersum MK (2007) Exploring multi-scale trade-offs between nature conservation, agricultural profits and landscape quality. A methodology to support discussions on land-use perspectives. Agric Ecosyst Environ 120:58-69

Hatchuel A, Weil B (2003) A new approach of innovative design: an introduction to $\mathrm{C}-\mathrm{K}$ theory. Proceedings of the international conference on engineering design (ICED'03), Stockholm, Sweden, pp 109-124

Hatfield JL, Hanson JD (eds) (2009) Proceedings of Farming Systems Design 2009, Monterrey (USA), 23-26 August 2009, $301 \mathrm{p}$

Herrero M, Fawcett RH, Dent JB (1999) Bio-economic evaluation of dairy farm management scenarios using integrated simulation and multiple-criteria models. Agr Syst 62:169-188

Herve D, Genin D, Migueis J (2002) A modelling approach for analysis of agro pastoral activity at the one-farm level. Agr Syst 71:187-206

Hevner AR, March ST, Park J, Ram S (2004) Design science in information systems research. MIS Quart 28(1):75-105

Howden SM, Soussana JF, Tubiello FN, Chhetri N, Dunlop M, Meinke HM (2007) Adapting agriculture to climate change. Proc Nat Acad Sci 104:19691-19696

Janssen S, van Ittersum MK (2007) Assessing farm innovations and responses to policies: a review of bio-economic farm models. Agr Syst 94:622-636

Jouven M, Baumont R (2008) Simulating grassland utilization in beef suckler systems to investigate the trade-offs between production and floristic diversity. Agr Syst 96:260-272

Keating BA, Carberry PS, Hammer GL, Probert ME, Robertson MJ, Holzworth D, Huth NI, Hargreaves JNG, Meinke H, Hochman Z, McLean G, Verburg K, Snow V, Dimes JP, Silburn M, Wang E, Brown S, Bristow KL, Asseng S, Chapman S, McCown RL, Freebairn DM, Smith CJ (2003) An overview of APSIM, a model designed for farming systems simulation. Eur J Agr 18:267-288

Kerr DV, Chaseling J, Chopping GD, Cowan RT (1999a) DAIRYPRO - a knowledge-based decision support system for strategic planning on sub-tropical dairy farms. II. Validation. Agr Syst 59:257-266

Kerr DV, Cowan RT, Chaseling J (1999b) DAIRYPRO - a knowledge-based decision support system for strategic planning on sub-tropical dairy farms. I. System description. Agr Syst 59:245-255

Klerkx L, Aarts N, Leeuwis C (2010) Adaptive management in agricultural innovation systems: the interactions between innovation networks and their environment. Agr Syst 103:390-400

Louhichi K, Kanellopoulos A, Janssen S, Flichman G, Blanco M, Hengsdijk H, Heckelei T, Berentsen P, Lansink AO, van Ittersum M (2010) FSSIM, a bio-economic farm model for simulating the response of EU farming systems to agricultural and environmental policies. Agr Syst 103:585-597

Machado CF, Morris ST, Hodgson J, Arroqui MA, Mangudo PA (2010) A web-based model for simulating whole-farm beef cattle systems. Comp Elec Agr 74:129-136

March J (1991) Exploration and exploitation in organizational learning. Organ Sci 2:1-13

Martin G, Felten B, Duru M (2011a) Forage rummy: a game to support the participatory design of adapted livestock systems. Environ Modell Softw 26:1442-1453 
Martin G, Martin-Clouaire R, Rellier JP, Duru M (2011b) A simulation framework for the design of grassland-based beef-cattle farms. Environ Modell Softw 26:371-385

Martin G, Theau JP, Therond O, Martin-Clouaire R, Duru M (2011c) Diagnosis and Simulation: a suitable combination to support farming systems design. Crop Pasture Sci 62:328-336

Martin-Clouaire R, Rellier JP (2009) Modelling and simulating work practices in agriculture. Int $\mathrm{J}$ Metadata Semantics Ontologies 4 (1):42-53

Matthews KB, Buchan K, Sibbald AR, Craw S (2006a) Combining deliberative and computer-based methods for multi-objective land-use planning. Agr Syst 87:18-37

Matthews KB, Wright IA, Buchan K, Davies DA, Schwarz G (2006b) Assessing the options for upland livestock systems under CAP reform: developing and applying a livestock systems model within whole-farm systems analysis. Agr Syst 90:32-61

Matthews KB, Rivington M, Blackstock K, McCrum G, Buchan K, Miller DG (2011) Raising the bar? - The challenges of evaluating the outcomes of environmental modelling and software. Environ Modell Softw 26:247-257

McCown RL (2002) Locating agricultural decision support systems in the troubled past and socio-technical complexity of 'models for management'. Agr Syst 74:11-25

Mosnier C, Agabriel J, Lherm M, Reynaud A (2009) A dynamic bioeconomic model to simulate optimal adjustments of suckler cow farm management to production and market shocks in France. Agr Syst 102:77-88

Mueller JP, Barbercheck ME, Bell M, Brownie C, Creamer NG, Hitt A, Hu S, King L, Linker HM, Louws FJ, Marlow S, Marra M, Raczkowski CW, Susko DJ, Wagger MG (2002) Development and implementation of a long-term agricultural systems study: challenges and opportunities. HortTechnology 12:362-368

Nielsen BK, Kristensen AR, Thamsborg SM (2004) Optimal decisions in organic steer production - a model including winter feed level, grazing strategy and slaughtering policy. Livest Prod Sci 88:239250

OECD (2005) Oslo manual: guidelines for collecting and interpreting innovation data, 3rd edn. OECD, Paris, $163 \mathrm{p}$

Pacini C, Giesen G, Wossink A, Omodei-Zorini L, Huirne R (2004a) The EU's Agenda 2000 reform and the sustainability of organic farming in Tuscany: ecological-economic modelling at field and farm level. Agr Syst 80:171-197

Pacini C, Wossink A, Giesen G, Huirne R (2004b) Ecologicaleconomic modelling to support multi-objective policy making: a farming systems approach implemented for Tuscany. Agric Ecosyst Environ 102:349-364

Pahl G, Beitz W (1988) Engineering design: a systematic approach, second edition. London/Berlin and New York, Design Council/ Springer-Verlag, $418 \mathrm{p}$

Pfister F, Bader HP, Scheidegger R, Baccini P (2005) Dynamic modelling of resource management for farming systems. Agr Syst 86:1-28

Prost L, Cerf M, Jeuffroy ML (2011) Lack of consideration for endusers during the design of agronomic models. A review. Agron Sustain Dev, in press, doi:10.1007/s13593-011-0059-4

Ramsden J, Gibbons JM (2009) Modelling agri-environment interactions and trade-offs using Farm-adapt - integration of models, investigation of scale, dynamics and uncertainty. In Aspects of Applied Biology: Integrated Agricultural Systems: Methodologies, Modelling and Measuring. pp 123-130

Rapidel B, Traore BS, Sissoko F, Lancon J, Wery J (2009) Experimentbased prototyping to design and assess cotton management systems in West Africa. Agron Sustain Dev 29(4):545-556

Rivington M, Matthews KB, Bellocchi G, Buchan K, Stockle CO, Donatelli M (2007) An integrated assessment approach to conduct analyses of climate change impacts on whole-farm systems. Environ Modell Softw 22:202-210
Romera AJ, Morris ST, Hodgson J, Stirling WD, Woodward SJR (2004) A model for simulating rule-based management of cowcalf systems. Comp Elec Agr 42:67-86

Rossi F, Van Beek P, Walsh T (2006) Handbook of constraint programming. Elsevier, Amsterdam

Rossing WAH, Corral J, Dogliotti S, Groot JCJ (2009a) Flexible re-use of system modules for whole-farm and landscape analysis and design with model explorer. In Proceedings of the Farming Systems Design 2009 International Symposium, August 23-26, 2009, Monterey, CA USA

Rossing WAH, Dogliotti S, Douthwaite B, Amendola RD, Cittadini ED, Contini C, Marescal Aguayo V, Moudry J, Omodei-Zorini L, Pacini GC (2009b) Shaping co-innovation for more effective farmer engagement by farming systems scientists: an illustration from Latin America. In Proceedings of the Farming Systems Design 2009 International Symposium, August 23-26, 2009, Monterey, CA USA

Rossing WAH, Jansma JE, De Ruijter FJ, Schans J (1997) Operationalizing sustainability: exploring options for environmentally friendly flower bulb production systems. Eur J Plant Pathol 103:217-234

Rossing WAH, Zander P, Josien E, Groot JCJ, Meyer BC, Knierim A (2007) Integrative modelling approaches for analysis of impact of multifunctional agriculture: a review for France, Germany and The Netherlands. Agric Ecosyst Environ $120: 41-57$

Rotz CA, Buckmaster DR, Comerford JW (2005) A beef herd model for simulating feed intake, animal performance, and manure excretion in farm systems. J Anim Sci 83:231-242

Rotz AC, Corson MS, Chianese DS, Coiner CU (2009) The integrated farming system model. Reference Manual. Version 3.2. http://ars. usda.gov/SP2UserFiles/Place/19020000/ifsmreference.pdf

Salinas H, Ramirez RG, Rumayor-Rodriguez A (1999) A whole-farm model for economic analysis in a goat production system in Mexico. Small Ruminant Res 31:157-164

Schön D (1983) The reflective practitioner: how professionals think in action. Basic Books, New York

Shaffer MJ, Bartling PNS, Ascough JC (2000) Object-oriented simulation of integrated whole farms: GPFARM framework. Comp Elec Agr 28:29-49

Simon HA (1969) The sciences of the artificial. The MIT Press, Cambridge

Stöckle CO, Donatelli M, Nelson R (2003) CropSyst, a cropping systems simulation model. Eur J Agr 18:289-307

Thompson J, Scoones I (2009) Addressing the dynamics of agri-food systems: an emerging agenda for social science research. Environ Sci Policy 12:386-397

Tittonell P, Corbeels M, van Wijk MT, Giller KE (2010) FIELD-A summary simulation model of the soil-crop system to analyse long-term resource interactions and use efficiencies at farm scale. Eur J Agr 32:10-21

van Calker KJ, Berentsen PBM, de Boer IMJ, Giesen GWJ, Huirne RBM (2004) An LP-model to analyse economic and ecological sustainability on Dutch dairy farms: model presentation and application for experimental farm "de Marke". Agr Syst 82:139-160

van Calker KJ, Berentsen PBM, Romero C, Giesen GWJ, Huirne RBM (2006) Development and application of a multi-attribute sustainability function for Dutch dairy farming systems. Ecol Econ 57:640-658

van de Ven GWJ, van Keulen H (2007) A mathematical approach to comparing environmental and economic goals in dairy farming: identifying strategic development options. Agr Syst 94:231-246

van Ittersum MK, Rabbinge R (1997) Concepts in production ecology for analysis and quantification of agricultural input-output combinations. Field Crop Res 52:197-208

van Wijk MT, Tittonell P, Rufino MC, Herrero M, Pacini C, de Ridder N, Giller KE (2009) Identifying key-entry points for strategic 
management of smallholder farming systems in sub-Saharan Africa using the dynamic farm-scale simulation model NUANCES-FARMSIM. Agr Syst 102:89-101

Vayssières J, Guerrin F, Paillat JM, Lecomte P (2009) GAMEDE: a global activity model for evaluating the sustainability of dairy enterprises Part I - Whole-farm dynamic model. Agr Syst 101:128-138

Vereijken P (1997) A methodical way of prototyping integrated and ecological arable farming systems (I/EAFS) in interaction with pilot farms. Eur J Agr 7:235-250

Veysset P, Bebin D, Lherm M (2005) Adaptation to Agenda 2000 (CAP reform) and optimisation of the farming system of French suckler cattle farms in the Charolais area: a model-based study. Agr Syst 83:179-202

Voinov A, Bousquet F (2010) Modelling with stakeholders. Environ Modell Softw 25:1268-1281

Weersink A, Jeffrey S, Pannell D (2002) Farm-level modeling for bigger issues. Rev Agr Econ 24:123-140

White TA, Snow VO, King WMcG (2010) Intensification of New Zealand beef farming systems. Agr Syst 103:21-35

Woodward SJR, Wake GC, McCall DG (1995) Optimal grazing of a multi-paddock system using a discrete time model. Agr Syst 48:119-139 